Francis Messner, Pierre-Henri Prélot, Jean-Marie Woehrling (éds.), Traité de droit français des religions Paris, Litec, 2003, XVII+1317 p. (bibliogr., index) (coll. « Traités du JurisClasseur »)

\title{
Émile Poulat
}

\section{(2) OpenEdition} Journals

Édition électronique

URL : http://journals.openedition.org/assr/972

DOI : $10.4000 /$ assr.972

ISSN : 1777-5825

Éditeur

Éditions de l'EHESS

\section{Édition imprimée}

Date de publication : 1 octobre 2003

Pagination : 63-170

ISBN : 2-222-96739-2

ISSN : 0335-5985

Référence électronique

Émile Poulat, «Francis Messner, Pierre-Henri Prélot, Jean-Marie Woehrling (éds.), Traité de droit français des religions ", Archives de sciences sociales des religions [En ligne], 124 | octobre - décembre 2003, document 124.68, mis en ligne le 25 octobre 2005, consulté le 24 septembre 2020. URL : http:// journals.openedition.org/assr/972 ; DOI : https://doi.org/10.4000/assr.972 
124.68

MESSNER (Francis),
PRÉLOT (Pierre-Henri),
WOEHRLING (Jean-Marie), éds.

Traité de droit français des religions. Paris, Litec, 2003, XVII+1317 p. (bibliogr., index) (coll. « Traités du Juris-Classeur).

En chantier depuis plus de dix ans, voici enfin abouti ce véritable monument du droit français, sans précédent : il suffit de remonter au Dalloz des cultes de 1911, jamais réédité, pour mesurer l'ampleur du travail exigé par cette véritable somme, grand format et caractères fins, qui a mobilisé 36 auteurs, presque tous juristes et presque tous universitaires. Une table des matières de près de 30 pages et précédée par une bibliographie relativement courte (près de trente pages, tout de même) et par un précieux index analytique qui renvoie aux 2960 numéros de l'ouvrage selon l'usage des juristes, dans une élégante présentation.

C'est dire l'ampleur et la complexité de la matière, distribuée en huit parties dont suffira ici l'énumération : 1) évolutions historiques et présentation des grandes religions en France; 2) droit international et droit constitutionnel ; 3) la liberté de religion et sa garantie ; 4) liberté de religion et droit privé ; 5) les institutions cultuelles ; 6) droit fiscal et patrimonial ; 7) la situation juridique des agents des institutions religieuses ; 8) enseignement et religion.

On y retrouve ainsi les biens, les personnes et les organisations, un peu moins - trop peu les activités (excepté l'enseignement), en droit public ou en droit privé, avec une attention particulière (l'initiative est venue de Strasbourg où elle a gardé son siège) au statut local de l'Alsace-Moselle, sans oublier l'articulation avec le droit européen et le droit international. On admire, sans être comblé. On n'épluche pas pareille entreprise dans le détail, tout en sachant qu'elle restera longtemps sans concurrence et que, même si le succès qu'on lui souhaite appelle une réédition, celle-ci sera substantiellement identique à la première. Pareil ouvrage ne se refait pas. On s'en tiendra donc ici à trois remarques générales.

En premier lieu, on relève l'absence des textes de référence, cités parcimonieusement. C'est un parti pris sage et sans doute nécessaire, sous peine d'aboutir à un monstre. Le corpus de ces textes ne peut que faire l'objet d'un autre ouvrage. Celui-ci existe, sous la direction de Bernard Jeuffroy et François Tricard, Liberté religieuse et régime des cultes en droit français. Textes, Paris, Cerf, 1996, difficile à manier, en cours de refonte. Entre le Traité et le corpus, il reste pourtant place pour une troisième entreprise : un Code des textes actuellement en vigueur.

En second lieu, les AA. parlent de droit des religions et de liberté de religion. C'est préférable à l'expression courante (attestée depuis deux siècles) "liberté religieuse », étrangère au vocabulaire juridique français, plus précis (en revanche, on pourrait admettre "libertés religieuses » au pluriel). Traditionnellement, le droit français distingue liberté de conscience et liberté de culte (ou d'exercice du culte). En tant que liberté publique, la liberté de religion n'existait pas sous l'Ancien Régime, était limitée sous le Concordat aux quatre cultes reconnus, et n'est devenue totale qu'avec la loi de 1905 en régime de laïcité. Sa reconnaissance juridique est indissociable de la liberté de conscience. La conscience est le grand absent de cet ouvrage : le mot manque à l'Index. En ce sens, le Traité reste confessionnellement marqué, malgré sa volonté de se situer dans le fil du droit civil, hors du droit canonique, de la discipline protestante ou de la loi coranique. II s'inscrit dans la lä̈cité au lieu d'en dériver.

En dernier lieu, un Code des textes actuellement en vigueur manifesterait une chronologie de plus de deux siècles. Un Traité comme celuici prend acte de cette durée historique. Mais l'histoire du droit renvoie à l'histoire et ses exigences autant qu'au droit. Le flou historique entraîne l'imprécision juridique dont le seuil de tolérance n'est pas le même dans l'enseignement, dans la pratique (administrative ou judiciaire) et dans la recherche. L'histoire que véhicule l'enseignement du droit des religions n'est trop souvent aujourd'hui qu'une vulgate, sans vérification, sans investigation. C'est peut-être le point faible de cette entreprise, faute de travaux préparatoires qui l'auraient encore retardée. $\mathrm{Ne}$ faisons pas la grimace.

Émile Poulat.

MICHELAT (Guy), POTEL (Julien), SUTTER (Jacques).

L'Héritage chrétien en disgrâce. Paris, L'Harmattan, 2003, 335 p. (Postface de Paul Ladrière) (cf. supra, pp. 39-48).

NEFONTAINE (Luc).

Le Protestantisme et la Franc-Maçonnerie. Des chemins qui se rencontrent. Genève, 